\title{
Drug discovery in Parkinson's disease: update and developments in the use of cellular models
}

This article was published in the following Dove Press journal:

International Journal of High Throughput Screening

29 June 2011

Number of times this article has been viewed

\section{Gaia Skibinski \\ Steven Finkbeiner \\ Gladstone Institute of Neurological Disease, San Francisco, CA, USA}

Correspondence: Steve Finkbeiner Gladstone Institute of Neurological Disease, Department of Neurological Disease, 1650 Owens Street, San Francisco, CA 94I58-226I, USA Tel + I 4 I5 7342508

$\mathrm{Fax}+\mathrm{I} 4153550824$

Email sfinkbeiner@gladstone.ucsf.edu
Abstract: Parkinson's disease is the second most common neurodegenerative disorder and is characterized by the degeneration of dopaminergic neurons within the substantia nigra. Dopamine replacement drugs remain the most effective treatment for Parkinson's disease but only provide temporary symptomatic relief. New therapies are urgently needed, but the search for a disease-modifying treatment and a definitive understanding of the underlying mechanisms of Parkinson's disease has been limited by the lack of physiologically relevant models that recapitulate the disease phenotype. The use of immortalized cell lines as in vitro model systems for drug discovery has met with limited success, because efficacy and safety too often fail to translate successfully in human clinical trials. Drug discoverers are shifting their focus to more physiologically relevant cellular models, including primary neurons and stem cells. The recent discovery of induced pluripotent stem cell technology presents an exciting opportunity to derive human dopaminergic neurons from patients with sporadic and familial forms of Parkinson's disease. We anticipate that these human dopaminergic models will recapitulate key features of the Parkinson's disease phenotype. In parallel, high-content screening platforms, which extract information on multiple cellular features within individual neurons, provide a networkbased approach that can resolve temporal and spatial relationships underlying mechanisms of neurodegeneration and drug perturbations. These emerging technologies have the potential to establish highly predictive cellular models that could bring about a desperately needed revolution in Parkinson's disease drug discovery.

Keywords: Parkinson's disease, cellular models, drug delivery

\section{Drug discovery in Parkinson's disease}

Parkinson's disease, the second most common neurodegenerative disorder, is characterized by motor symptoms, including rigidity, bradykinesia, and tremor. These symptoms are the direct result of a nigrostriatal dopamine deficit, due to the selective loss of dopaminergic neurons in the substantia nigra. Other prominent neuropathological features include dystrophic neurites and intracellular proteinaceous inclusions called Lewy bodies. ${ }^{1}$ Approximately $1 \%-2 \%$ of those over the age of 65 years suffer from Parkinson's disease, and the incidence increases with age. ${ }^{2}$ The present annual cost of health care for patients with Parkinson's disease is estimated to exceed $\$ 5.6$ billion in the US (National Institute of Neurological Disorders and Stroke). With the rapid increase in worldwide life expectancy, the prevalence of Parkinson's disease is expected to double by $2030 .^{3}$

The selective loss of dopaminergic neurons in the substantia nigra has focused treatments towards dopamine replacement drugs, such as levodopa. Although it 
was identified almost 45 years ago, ${ }^{4}$ levodopa remains the principal and most effective treatment for Parkinson's disease. However, as the disease progresses and more dopaminergic neurons are lost, the efficacy of levodopa diminishes, and patients experience increasing fluctuations in motor symptoms, including dyskinesias. Furthermore, dopamine replacement drugs fail to address the degeneration observed in other brain areas, such as the locus coeruleus and cerebral cortex, ${ }^{5,6}$ and the wide range of autonomic symptoms noted in patients with Parkinson's disease. ${ }^{7}$ Ultimately, disease-modifying treatments are needed that address both the motor and nonmotor symptoms of Parkinson's disease.

Despite increasing investment in biomedical research by industry and government, ${ }^{8}$ the success rate of new drugs in clinical trials is dropping. ${ }^{9}$ Drug discovery in Parkinson's disease is no exception, and promising new compounds validated at the preclinical stage often fail during development and expensive clinical trials. ${ }^{10}$ For example, sarizotan, an antidyskinesia drug, was successful in preclinical and Phase II trials, yet failed in Phase III trials. ${ }^{11}$ These are costly failures, considering that discovering and developing a new drug is now estimated at US\$ 800 million. ${ }^{12}$ Attrition rates of late-stage drug candidates could be modestly reduced by improving the design of clinical trials. ${ }^{13}$ However, academic and industry scientists acknowledge that, ultimately, to increase the success rate and reduce the financial burden of drug discovery, improvements should be focused on the drug discovery pipeline itself. In particular, they should be focused on identifying and validating relevant targets and characterizing candidate drugs. ${ }^{14}$

During the last 20 years, cellular models of neurodegenerative diseases have undergone many evolutionary changes. Conventional drug discovery strategies utilized genetically engineered and immortalized cell lines to develop cell-based assays. In these systems, the cell type is subservient to the limitations of the assay technology. The focus is now shifting towards developing cell-based assays that more faithfully recapitulate characteristics of the disease phenotype, leading to better target identification and predictions of drug efficacy and toxicity. Consequently, primary neurons and stem cells are increasingly recognized as powerful tools for drug discovery. ${ }^{14}$ Parallel developments in high-throughput screening and high-content screening platforms, which capture multiparametric features within single cells, have enabled cellular signatures to be defined for disease states and toxic activities of compounds that are screened..$^{15}$

\section{Modeling Parkinson's disease for drug discovery: too many targets}

Drugs against novel targets are estimated to have a $50 \%$ greater failure rate and create less value than those developed against validated targets. ${ }^{16}$ As a result, much of the drug discovery in Parkinson's disease has focused on enhancing the efficacy of levodopa and minimizing its side effects. ${ }^{17}$ However, levodopa provides only symptomatic improvement, and has little effect on the multisystem neuronal dysfunction and deterioration that occur in Parkinson's disease. Novel drug targets are needed if we are to develop effective disease-modifying treatments for Parkinson's disease. To date, no single mechanism or cause of sporadic Parkinson's disease, which makes up the vast majority of cases, has been identified. However, insights into mechanisms of the pathogenesis of Parkinson's disease have emerged from mutations in several genes that associate with familial forms of the disease. They encode leucinerich repeat kinase 2 (LRRK2), ${ }^{18,19} \alpha$-synuclein, ${ }^{20}$ parkin, ${ }^{21}$ DJ-1, ${ }^{22}$ (PTEN)-induced kinase 1 (PINK1), ${ }^{23}$ and ATP13A2 ${ }^{24}$ (Table 1). These genes implicate several cellular processes as potential mechanisms underlying familial and sporadic Parkinson's disease, including oxidative stress, mitochondrial dysfunction, perturbations in proteostasis, inflammation, and protein phosphorylation. ${ }^{25,26}$ It is unknown which mechanism or risk factor, if any, plays the dominant role in Parkinson's disease. As a result, the validation and exploration of these targets remain a significant bottle-neck in the drug discovery pipeline for Parkinson's disease.

Defining the mechanisms of neurodegeneration in Parkinson's disease has been hampered by our limited access to the specific neuronal populations most affected by the disease. Pathological studies on postmortem tissue from patients provided hints about the cellular events underlying neurodegeneration in Parkinson's disease, such as Lewy body formation ${ }^{27}$ and mitochondrial dysfunction. ${ }^{28}$ However, these are only snapshots of cellular events at the end of the disease progression, when most of the dopaminergic neurons have already been destroyed. Furthermore, there is no way of knowing which of these cellular features are primary or secondary to the initial pathogenic insult, and which are incidental events or homeostatic responses exhibited by injured neurons. ${ }^{29}$

Animal and cellular models attempt to recapitulate various aspects of the Parkinson's disease phenotype, with mixed success. Animal models of the disease have been generated by injecting neurotoxins and by transgenic expression of associated mutations. ${ }^{30}$ Toxin models induce nigrostriatal cell loss, one of the key pathological traits of Parkinson's disease. 
Table I Gene loci associated with Parkinson's disease

\begin{tabular}{|c|c|c|c|c|}
\hline PARK loci & Gene & Types of PD & Mutations & Function \\
\hline PARKI/PARK4 & SNCA & $\begin{array}{l}\text { AD, early onset } \\
\text { and sporadic }\end{array}$ & $\begin{array}{l}\text { A53T, A30P, E46K, duplications } \\
\text { and triplications } \sim 2 \% \text { of familial } \\
\text { parkinsonism }{ }^{109}\end{array}$ & $\begin{array}{l}\text { Presynaptic protein implicated in } \\
\text { neurotransmitter release }{ }^{122}\end{array}$ \\
\hline PARK2 & Parkin & $\begin{array}{l}\text { AR, juvenile and early onset } \\
\text { and sporadic }\end{array}$ & $\begin{array}{l}>100 \text { mutations almost } 50 \% \text { of } \\
\text { early onset } A R P D, \sim 20 \% \text { isolated } \\
\text { juvenile PD }\end{array}$ & $\begin{array}{l}\text { Ubiquitin ligase, targets protein to the } \\
\text { proteasome for degradation }{ }^{124} \text { and } \\
\text { recruited to depolarized mitochondria } \\
\text { to aid mitophagy }{ }^{125}\end{array}$ \\
\hline PARK6 & PINKI & AR, early onset & $\begin{array}{l}>40 \text { point mutations, rare large } \\
\text { deletions } 1 \%-9 \% \text { early onset }{ }^{126}\end{array}$ & $\begin{array}{l}\text { Preserve mitochondria integrity }{ }^{127} \text { and } \\
\text { required for Parkin-mediated mitophagy }{ }^{128}\end{array}$ \\
\hline PARK7 & DJI & $A R$, early onset & $\begin{array}{l}>10 \text { point mutations and large } \\
\text { deletion }<1 \% \text { early onset }\end{array}$ & $\begin{array}{l}\text { Redox-sensitive molecular chaperone } \\
\text { preventing aggregation of } \alpha \text {-synuclein }{ }^{38}\end{array}$ \\
\hline PARK8 & LRRK2 & $A D$, late onset and sporadic & $\begin{array}{l}>40 \text { missense mutations, at least } 7 \\
\text { are pathogenic } 10 \% \text { AD familial } \\
\text { cases and } 3.6 \% \text { sporadic } \text { PD }^{129}\end{array}$ & $\begin{array}{l}\text { Kinase and GTPase activity. Implicated } \\
\text { in signaling pathways including apoptosis, } \\
\text { regulation of cytoskeleton, MAPK } \\
\text { signaling and protein translation }{ }^{130}\end{array}$ \\
\hline PARK9 & ATPI $3 A 2$ & $\begin{array}{l}\text { AR, juvenile Kufor-Rakeb } \\
\text { syndrome and early onset PD }\end{array}$ & $>5$ point mutations & Lysosomal P type ATPase ${ }^{24}$ \\
\hline
\end{tabular}

Abbreviations: $A D$, autosomal dominant; $A R$, autosomal recessive; PD, Parkinson's disease; MAPK, mitogen-activated protein kinase.

They have been criticized because the rate of neurodegeneration is far greater than that of humans with Parkinson's disease. ${ }^{31}$ However, continuous low-level administration of 1-methyl-4-phenyl-1,2,3,6-tetrahydropyridine mimics more progressive behavioral changes and inclusion formation characteristic of Parkinson's disease.$^{32}$ In the past, animal models harboring genetic mutations that mimic inherited forms of Parkinson's disease have been limited in their ability to recapitulate the classical features of the disease. ${ }^{30}$ More recently, transgenic mouse models involving the expression of $\alpha$-synuclein and LRRK2 developed distinct behavioral changes, dopaminergic cell loss and pathological inclusions reminiscent of Parkinson's disease. ${ }^{33,34}$ Although animal models are often used to validate the efficacy and safety of novel drugs, they are of limited use in unraveling the complexities of cellular mechanisms and impractical for high-throughput screening and other drug development stages, such as toxicological dose-response studies.

\section{Cell models for drug development}

This review describes current cell models that have been developed to recapitulate traits of pathogenesis of Parkinson's disease and their applicability to high-throughput screening. We will also describe emerging cellular technologies that have significant potential to improve drug discovery.

\section{Immortalized cell lines}

Traditionally, recombinant immortalized cells have been a popular choice for drug discovery in cell-based assays. ${ }^{35}$ These cells can be grown in virtually unlimited quantities, are not labor-intensive, and can be stored frozen to limit replicative senescence. ${ }^{36}$ They provide a relatively homogenous target expression system that leads to less variable screening and can be genetically manipulated to express or knock down a target or express a reporter. Several cell lines display characteristics of dopaminergic neurons (Table 2) and have provided valuable insights into cellular mechanisms of Parkinson's disease.

Human neuroblastoma cell lines, including SHSY5Y, SK-N-SH, and SK-N-MC, have often been used to model cellular traits of Parkinson's disease, including the formation of Lewy bodies. ${ }^{37}$ Many studies have taken advantage of nonhuman cell lines to probe the mechanisms in Parkinson's disease. For example, a murine central nervous system catecholaminergic-derived cell line was used to show that DJ-1, a protein involved in early onset parkinsonism,${ }^{22}$ inhibits formation of $\alpha$-synuclein aggregates. ${ }^{38} \mathrm{~A}$ rat dopaminergic cell line, N27, was used to investigate the role of dimer formation in $\alpha$-synuclein aggregation ${ }^{39}$ and human mutant $\alpha$-synuclein-mediated toxicity. ${ }^{40} \mathrm{PC} 12$ cells derived from a rat pheochromocytoma were used to investigate the role of autophagy and the proteasome degradation pathway during $\alpha$-synuclein-mediated apoptosis. ${ }^{41}$

However, ultimately, these immortalized cell lines are not authentic dopaminergic neurons. A renewable source of human dopaminergic neurons is of particular interest for drug discovery and cell transplantation therapy in Parkinson's disease. Attempts have been made to develop human midbrain cell lines. For example, MESC2.10 was derived from the ventral mesencephalon of an 8-week-old human 
Table 2 Sources and examples of immortalized cell lines used in Parkinson's disease research

\begin{tabular}{|c|c|c|c|c|}
\hline & Source & Examples & Differentiation & Dopaminergic like properties \\
\hline Mouse & $\begin{array}{l}\text { Central nervous systema } \\
\text { (catecholaminergic) }\end{array}$ & CAD & Serum deprivation & Displays neurites and expresses $\mathrm{TH}$ \\
\hline Mouse & $\begin{array}{l}\text { Fusion of embryonic midbrain } \\
\text { and neuroblastoma cell line }\end{array}$ & MN9D & N-butyric acid & Expresses TH and synthesizes, stores, and releases DA \\
\hline Rat & Midbrain & N27 & Db-cAMP and DHEA & Displays neurites and expresses TH and DAT \\
\hline Rat & Pheochromocytoma & $\mathrm{PCI} 2$ & Nerve growth factor & Neuronal processes and produces DA \\
\hline Human & Neuroblastoma & $\begin{array}{l}\text { SHSY5Y, SK-N-SH, } \\
\text { SK-N-MC }\end{array}$ & Retinoic acid or TPA & Display neurites and expresses TH, DBH, and DAT \\
\hline Human & Carcinoma & Ntera2 & Retinoic acid & Expresses TH, DAT, and dopamine D2 receptor \\
\hline Human & Embryonic ventral midbrain & MESC2.10 & $\begin{array}{l}\text { Tetracycline, db-cAMP, } \\
\text { and GDNF }\end{array}$ & $\begin{array}{l}\text { Exhibits neurites, electrically active, expresses } \mathrm{TH} \text { and } \\
\text { DAT, and produces DA }\end{array}$ \\
\hline Human & Fetal ventral midbrain & ReNcell VM & Db-cAMP and GDNF & Expresses $\mathrm{TH}$ and displays electrically active potentials \\
\hline
\end{tabular}

Abbreviations: CAD, Cath A-derived; DA, dopamine; DAT, dopamine transporter; db-cAMP, dibutyryl cyclic AMP; DBH, dopamine-beta-hydroxylase; DHEA, dehydroepiandrosterone; GDNF, glial cell line-derived neurotrophic factor; TPA, 12-O-tetradecanoylphorbol-13-acetate; TH, tyrosine hydroxylase.

embryo and immortalized by ectopic myc expression. Upon differentiation, these cells exhibit neurites, express markers of mature neurons and are electrically active. A subpopulation of these cells also expresses tyrosine hydroxylase and dopamine transporters, produces dopamine, ${ }^{42}$ and has been used to investigate the role of $\alpha$-synuclein in the impairment of vesicular dopamine storage. ${ }^{42}$

Despite the scalability and genetic malleability of these immortalized cell lines, their genetic and molecular phenotypes are significantly different from native dopaminergic neurons in vivo. ${ }^{43,44}$ Importantly, the effects of potential drugs or therapies on recombinant molecular targets expressed in immortalized cells may not be fully analogous to physiologic effects in vivo ${ }^{45}$ In fact, the success rate of compounds developed against central nervous system disorders is estimated to be only $8 \%$, with lack of efficacy and safety being major reasons for this high attrition rate. ${ }^{46}$ As a result, there is a growing need for the development of novel predictive cellular models.

\section{Primary cells}

Primary neurons are post-mitotic differentiated cells and are functionally and morphologically more similar to those found in patients. Cellular phenotype is critical in the pharmacokinetics and pharmacodynamics of a drug compound, and this is particularly relevant to neurons, where the complex interplay among ion channels, intracellular signaling pathways, and the regulation of gene expression might be essential for accurately identifying novel compounds. Consequently, primary cell systems are more effective at predicting human responses to novel drugs. ${ }^{47}$

Primary dopaminergic neurons can be dissociated from the midbrain of embryonic and postnatal rats or mice. ${ }^{48}$
However, studies with embryonic cultures have been limited; dopaminergic neurons make up less than $1 \%$ of the total culture $^{49}$ and are immature. The characteristics they display in vitro vary significantly with the culture conditions. ${ }^{50}$ In midbrain cultures derived from postnatal animals, up to $50 \%$ of the cells are dopaminergic neurons, and these cells faithfully recapitulate electrophysiological and morphological properties of dopaminergic neurons in vivo. ${ }^{51}$ Rodent primary dopaminergic neurons have been invaluable in studies of Parkinson's disease-specific toxicity and Lewy body formation. ${ }^{52,53}$ Similar to immortalized cell lines, primary cells can be used to evaluate endogenous targets or be genetically modified to express recombinant targets or reporters. Primary midbrain dopaminergic neurons have also been obtained from human fetal tissue. However, the limited availability and ethical implications of obtaining and using these cells make them less attractive. Although most studies with human dopaminergic neurons have involved cell replacement therapies as a treatment for Parkinson's disease patients, ${ }^{54}$ these cells have been used to model the dopaminergic specificity of $\alpha$-synuclein-mediated toxicity and Lewy body formation. ${ }^{56}$

The use of primary neurons for drug discovery permits the simultaneous analysis of multiple cell types. These cultures are significantly more physiologically relevant than immortalized cells, ${ }^{14}$ but primary dopaminergic cells have shortcomings, including their significant handling demands, the inability to freeze the cells, and greater expense because they are derived directly from animals. Furthermore, genetic manipulation is more difficult in primary neurons than in immortalized cell lines, and the variability is greater when cultures are prepared on different days and by different investigators. Of particular relevance to high-throughput 
screening, only small numbers of cells can be derived from each dissection. To some extent, these limitations have been outweighed by the development of automated fluorescence microscopy and high-content screening, which require fewer cells for each data point (described in more detail below), but logistical challenges remain.

\section{Stem cells}

Stem cells have been used for drug discovery since the $1970 s{ }^{57}$ The use of stem cells avoids several of the drawbacks of primary neurons. ${ }^{58}$ They can be propagated indefinitely and grown to the required scale, similar to immortalized cell lines. Yet they retain pluripotency and can differentiate into neurons that are genetically and functionally analogous to those in vivo. ${ }^{59}$ Parkinson's disease patients display a well-characterized selective loss of dopaminergic neurons in the midbrain, ${ }^{60}$ and dopaminergic neurons derived from embryonic stem cells and neural stem cells are a renewable source for potential cell replacement therapies. Furthermore, dopaminergic neurons derived from stem cells could lead to more relevant and accurate models for studies of disease mechanisms and drug discovery.

\section{Embryonic stem cells}

Embryonic stem cells are derived from the inner mass of the blastocyst. Dopaminergic neurons have been differentiated from mouse embryonic stem cells by several protocols, including coculturing with stromal PA-6 cells ${ }^{61,62}$ and embryoid body-based lineage selection. ${ }^{63}$ Dopaminergic neurons derived from mouse embryonic stem cells have pharmacological phenotypes similar to primary dopaminergic neurons. ${ }^{64}$ Furthermore, transplantation of embryonic stem-derived neural precursors or dopaminergic neurons rescues behavioral deficits in animal Parkinson's disease models. ${ }^{65-67}$ Human embryonic stem cells have also been successfully differentiated into dopaminergic neurons in vitro. ${ }^{68-70}$ Compared with mouse embryonic stem cells, human embryonic stem cells are more difficult to grow and expand, and their differentiation into dopaminergic-specific neurons is less robust. For example, in human embryonic stem cell-derived dopaminergic neurons, tyrosine hydroxylase expression decreases in vitro, and after transplantation, no tyrosine hydroxylase-positive cells were detected, despite good survival. ${ }^{68}$ However, recent progress has been made in developing more robust protocols for large-scale generation of dopaminergic neurons from human embryonic stem cells ${ }^{71}$ and differentiation of specific subtypes of dopaminergic neurons, including the substantia nigra A9 type, that appear to be more vulnerable to degeneration in Parkinson's disease. ${ }^{72}$

\section{Neural stem cells}

Dopaminergic neurons can also be derived from neural stem cells isolated from neuronal tissues in more advanced developmental stages than embryonic stem cells. Neural stem cells have been cultured from embryonic, fetal, and adult mammals, including humans. ${ }^{73,74}$ The limited accessibility to human tissue, as well as the difficulty in growing these cells and maintaining a stable phenotype across passages,${ }^{75}$ has made the use of human-derived neural stem cells challenging. However, the development of immortalized human neural stem cell lines has significantly facilitated long-term culturing of these cells in an undifferentiated state. When needed, immortalized neural stem cells can be expanded and differentiated into the appropriate type of neuron. ${ }^{76}$ One such cell line, ReNcell VM, is an immortalized human fetal neural stem cell line derived from the ventral mesencephalon by transduction with v-myc. Differentiation leads to neurons that express tyrosine hydroxylase and generate action potentials. ${ }^{77}$ A recent study with ReNcell VM cells demonstrated that loss of PINK1 leads to mitochondrial dysfunction, increased oxidative stress and lysosomal pathology, which subsequently led to increased cell death. ${ }^{78}$

\section{Genetic manipulation of stem cells}

In addition to self-renewal and pluripotency, embryonic stem cells are amendable to genetic manipulation. Inserting selectable genes under the control of cell type-specific promoters allows the enrichment of specific cell populations. This is particularly helpful because the differentiation of embryonic stem cells is asynchronous, and cells undergoing differentiation are heterogeneous. ${ }^{79}$ For example, selection for neuronal cells have been accomplished by placing a neomycin gene under the control of the Sox 1 promoter. ${ }^{80}$ Another group inserted green fluorescent protein into the DAT locus in mouse embryonic stem cells; in this way, live dopaminergic neurons can be selected based on green fluorescent protein fluorescence. ${ }^{81}$ Furthermore, expression of specific genes, such as Nurr1 in embryonic stem cell lines, enables a greater enrichment of dopaminergic neurons during differentiation. ${ }^{65}$

Embryonic stem cells have also been modified to dissect mechanisms of genetic models of Parkinson's disease, such as mutant $\alpha$-synuclein-mediated toxicity. ${ }^{82}$ In addition, disease-causing mutations can be introduced into embryonic stem cells, or embryonic stem cells can be isolated from 
animal models of the disease. For instance, embryonic stem cells from knock-out DJ-1 mouse embryos were differentiated into dopaminergic neurons. DJ-1-deficient cells had a lower survival rate and were more sensitive to oxidative stress, suggesting that DJ-1 is an essential component of the oxidative stress response. ${ }^{83}$

\section{Applying stem cells to high-throughput screening}

Stem cells are an attractive alternative for high-throughput screening. Embryonic stem cell-derived neurons have been used in high-throughput screening to assay more than 2.4 million small molecules for AMPA potentiation and toxicity. ${ }^{84-86}$ Importantly, these neurons demonstrate pharmacological responses similar to those of primary rat neurons. ${ }^{84}$ The ability of stem cells to differentiate into clinically relevant neuron-specific populations makes them ideal for identifying drugs that are specific for targets and also potentially for cell types. Although mouse stem cells have advantages over primary cells as a drug discovery tool, ${ }^{58}$ especially in terms of scalability, questions remain about how well drug evaluations in mouse cells translate to efficacy and safety in humans. Growing human stem cells to the scale required for drug discovery is difficult and has been hindered by availability and ethical and political constraints.

\section{Induced pluripotent stem cells}

In 2006, the Yamanaka group discovered a group of genes that directly reprogram fibroblast cells to embryonic stem cell-like cells, known as induced pluripotent stem cells. ${ }^{87,88}$ The discovery of human induced pluripotent stem cells opened the door to a new generation of cell-based models for human neurological diseases, including Parkinson's disease. Established protocols that promote differentiation of human embryonic stem cells have been adapted for induced pluripotent stem cells, allowing the induction of these cells into dopaminergic neurons. ${ }^{89,90}$ Progress has been made in characterizing the dopaminergic phenotype and function of these cells. ${ }^{91}$

\section{Induced pluripotent stem cells from individual patients}

One of the biggest advantages of induced pluripotent stem cells is that they can be easily derived from patients with sporadic and familial forms of the disease. In the past, obtaining patient tissues to model neurodegenerative disease was very difficult. Human embryonic stem cell lines had been derived from affected in vitro fertilization embryos of patients with Huntington's disease, an incurable neurodegenerative disorder. ${ }^{92}$ However, these cells are collected before symptoms manifest and cannot be expanded into new embryonic stem cell lines. In Parkinson's disease research, skin biopsies from patients with mutations in PINK1 were used to generate primary human fibroblasts. Although these cells provided insight into mechanisms of PINK1-specific degeneration, ${ }^{93,94}$ it is unclear how results in fibroblasts mimic the processes of degeneration in dopaminergic neurons. The ability to grow induced pluripotent stem cell-derived neurons from patients provides a direct link between the human tissues and the disease model in vitro. Several groups have already derived induced pluripotent stem cells from Parkinson's disease patients and differentiated them into dopaminergic neurons. ${ }^{90,95}$ Upon transplantation into the striatum of a rodent model of Parkinson's disease, these cells were functional and developed dendritic arborization expected of mature dopaminergic neurons. Furthermore, the transplantation of these cells effectively rescue motor deficits in these animals. ${ }^{96}$

\section{Future possibilities with induced pluripotent stem cells}

It is unknown whether patient-derived induced pluripotent stem cell-based models of Parkinson's disease will recapitulate the characteristic pathology found in Parkinson's disease, including the formation of Lewy bodies. Due to the late onset of Parkinson's disease symptoms, the brief lifetime of the reprogrammed cells may be insufficient to observe any pathogenic process. Also, the subtype of dopaminergic neuron, specifically the substantia nigra A9 neuron, is critical for reestablishing new dopaminergic terminals and restoring motor function in midbrain transplantations. ${ }^{97}$ Therefore, induced pluripotent stem cells might need to be pushed towards differentiating substantia nigra A9 type dopaminergic neurons, ${ }^{72}$ before a Parkinson's disease-specific phenotype is observed. On the other hand, patients with Parkinson's disease do not display motor deficits until they have lost $50 \%-60 \%$ of their dopaminergic neurons and $70 \%-80 \%$ of their striatal dopaminergic terminals. ${ }^{98-100}$ Thus, cellular dysfunction might occur well before symptoms are visible. So far, dopaminergic neurons derived from induced pluripotent stem cells of five patients with idiopathic Parkinson's disease have showed no obvious differences with control cells. ${ }^{90}$ However, a recent encouraging paper showed that dopaminergic neurons derived from induced pluripotent stem cells of a patient with the most common LRRK2 mutation, G2019S, had enhanced sensitivity to an array of cellular stresses and accumulated $\alpha$-synuclein. ${ }^{101}$ Validation of disease-associated phenotypes 
may involve knocking down the underlying genetic mutations in an attempt to rescue the disease phenotypes. An exciting new technology involving homologous recombination combined with zinc finger nucleases may allow for targeted genetic modification of induced pluripotent stem cells. ${ }^{102,103}$ The ability to disrupt genes specifically and insert transgenes might allow gain or loss of function experiments to facilitate precisely the validation of specific targets and pathways in these cells.

Induced pluripotent stem cells have the potential to resolve many unanswered issues. For example, ethnicity is important for the penetrance of Parkinson's diseaseassociated mutations. The frequency of the G2019S LRRK2 mutation in northern European cases of Parkinson's disease is less than 5\%. However, in North African and Ashkenazi Jews, it is $40 \%$ and $18 \%$, respectively. ${ }^{104}$ Unlike available human-derived embryonic stem cell lines, which represent a limited spectrum of ethnicity, ${ }^{105}$ induced pluripotent stem cells can be isolated easily from individuals from a broad range of ethnic backgrounds, enabling investigation into differences in ethnic susceptibility to disease-associated mutations and accelerating progress towards individualized medicine.

Induced pluripotent stem cells will also allow us to examine more subtypes of Parkinson's disease. Existing cellular models are based on inherited forms of the disease. However, only 5\%-10\% of patients with Parkinson's disease suffer from monogenic forms of the disease. Most develop idiopathic or sporadic Parkinson's disease. ${ }^{106}$ Parkinson's disease is a multifaceted and complex disorder, ${ }^{107}$ but disease subtypes can be defined, based on age of onset, dominant clinical features, and progression rate. ${ }^{108}$ Multiple genetic risk factors likely contribute to the development of sporadic Parkinson's disease and disease subtypes. ${ }^{109}$ Routinely deriving induced pluripotent stem cells from sporadic patients will potentially enable the engineering of cellular models that faithfully incorporate all these risk factors.

Like embryonic stem cell lines, induced pluripotent stem cells from different patients vary in their propensity to differentiate. ${ }^{96,110}$ Embryonic stem and induced pluripotent stem cells maintain their genomic information, but they might lose critical epigenetic signals. ${ }^{88}$ In the future, this variation might be harnessed to distinguish between genetic and environmental variables that contribute to sporadic Parkinson's disease. However, variation has been observed in different induced pluripotent stem cell clones derived from the same individual. ${ }^{111}$ The viral vectors used to transduce reprogramming factors could be one source of this variation..$^{90}$
In a recent study, removing the reprogramming genes from an induced pluripotent stem cell line derived from a Parkinson's disease patient led to expression patterns that were more similar to human embryonic stem cells than the parentalinduced pluripotent stem line..$^{90}$ For induced pluripotent stem cells to become "mainstream" as a tool in drug discovery, they must be generated without the genomic integration of reprogramming vectors.

Currently, the protocols for differentiating these cells are costly and inefficient, and the resulting cellular subtypes have considerable variability. However, ongoing research seeks new ways to differentiate induced pluripotent stem cells into specific neuronal subtypes and to characterize these neurons at the molecular and functional levels. Most importantly, neuronal phenotypes found in these cells must recapitulate patient phenotypes, and these phenotypes must be validated in cells derived from multiple patients.

\section{Modeling the cellular complexity of Parkinson's disease}

A successful cell-based model for drug discovery would facilitate identification of relevant therapeutic targets and compounds to modulate those targets. An ideal model would accurately predict the efficacy and safety of these drugs in humans, with high predictive value for clinical trials. More effective preclinical evaluation would significantly lower the cost of drug development by reducing the number of animal validation studies needed in later testing and would result in better drug success rates in expensive clinical trials.

Most cell-based high-throughput screening involve assays that are conducted on all the cells in a particular sample well, quantifying relatively simple readouts that focus on the target or single endpoints. For example, using systems, such as the Flash Cytometer ${ }^{\circledR}$ (Trophos, Marseille, France), automated fluorescence measurements can be used to quantify toxicity or other cellular parameters. This type of system is applicable to the rapid screening of thousands of compounds. A recent study screened approximately 40,000 compounds in primary motor neurons for candidates that promote neuronal survival and neurite outgrowth. ${ }^{112}$ However, conventional well-based high-throughput screening approaches are poorly suited to deal with the increased heterogeneity and well-to-well variability of primary neurons and stem cells.

The emergence of high-content screening, which measures multiple neuronal features within single cells, for thousands of cells, ${ }^{113,114}$ provides a new level of sensitivity in screening. These systems combine high-resolution fluorescence and confocal imaging platforms, with powerful 
image analysis algorithms (eg, Harmony ${ }^{\mathrm{TM}}$ software from PerkinElmer [Waltham, MA] or Cellomics Array Scan ${ }^{\circledR}$ from Thermo Scientific [Rockford, IL]) that select and analyze single cells, according to predefined morphology or intensity parameters, including neurite extension, cell shape, organelle morphology, or translocation of fluorescently labeled proteins. However, despite significant progress, more vigorous and detailed image analysis algorithms with less manual input are still required. ${ }^{115,116}$

The ability to track individual neurons over the course of the disease process, combined with longitudinal measurements of multiple cellular features within each of these cells, leads to a remarkable new level of sensitivity and the ability to determine the predictive relationships between cellular changes and the ultimate fate of the cell. ${ }^{117-119}$ Conventional screening systems that take static snapshots of the disease state are poorly suited to capture the complexity and heterogeneity of cellular systems. In addition to the cell-to-cell variability of primary neurons and stem cells, the biology of neurodegeneration and the differentiation of stem cells unfold asynchronously within individual cells to produce additional heterogeneity.

We applied this new approach to resolve a long-standing controversy over the role of inclusion bodies in the pathogenesis of Huntington's disease ${ }^{118}$ and to reveal temporal relationships between the ubiquitin proteasome system and inclusion body formation. ${ }^{120}$ In addition to determining qualitative relationships, this approach also simultaneously quantifies the contribution of one or more cellular changes on the ultimate fate of the cell. ${ }^{119}$ We showed that cytoplasmic mislocalization of TDP43, a major protein component of neuronal aggregates characteristic of amyotrophic lateral sclerosis and frontotemporal dementia is critical for disease pathogenesis. ${ }^{121}$

This new technology also offers powerful new approaches for high-throughput screening. ${ }^{115}$ The added sensitivity (100-fold greater compared with snapshot-based conventional high-throughput screening ${ }^{117}$ ) makes it much more feasible to use primary neurons, including those differentiated from human induced pluripotent stem cells, as a screening platform because many fewer cells are needed to detect significant effects. The ability of the system to follow thousands of individual neurons longitudinally allows each cell to serve as its own control, effectively managing the cell-to-cell and well-to-well variability that plagues cell-based high-throughput screening. These advances make this technology well suited to pursue genome-wide RNAi screening in primary neurons to identify relevant therapeutic targets and to conduct screens of moderately sized small-molecule libraries to do drug discovery. Finally, the measures of fate that the system provides are sufficiently quantitative that structure-activity relationships among chemical series can be delineated, and some lead optimization can occur even if the target of the small molecule remains to be identified.

\section{Conclusion}

A wide range of cellular systems has been used to model and investigate the underlying molecular mechanisms of Parkinson's disease. Each system has its own advantages and limitations for drug discovery. Improving drug discovery will require more relevant cellular models and advanced screening platforms that analyze neurons at the level of single cells, enabling multivariable modeling of disease-associated mechanisms. However, a question remains whether one model system can model the multifaceted phenotype of Parkinson's disease. Now, induced pluripotent stem cells from familial and sporadic Parkinson's disease patients that are differentiated into dopaminergic neurons hold great promise for faithful human cellular models that recapitulate essential features of Parkinson's disease. Even so, further development and characterization of these cells is required before their full potential for drug development can be realized. Ultimately, more physiologically relevant models that capture the complexity of Parkinson's disease can only lead to better decisions and translation at all levels of drug discovery.

\section{Acknowledgments}

We thank the members of the Finkbeiner laboratory for their generous support and advice. We thank G Howard for editorial assistance and K Nelson for administrative assistance. This work was supported by the Hillblom Foundation (to GS), a National Institutes of Health National Institute on Aging grant, the Taube-Koret Center for Huntington's Disease Research, two National Institutes of Health National Institute of Neurological Disorders and Stroke grants, and the Keck Foundation (to SF).

\section{Disclosure}

The authors report no conflicts of interest in this work.

\section{References}

1. Wakabayashi K, Mori F, Takahashi H. Progression patterns of neuronal loss and Lewy body pathology in the substantia nigra in Parkinson's disease. Parkinsonism Relat Disord. 2006;12 Suppl 2:S92-S98.

2. De Lau LM, Giesbergen PC, de Rijk MC, Hofman A, Koudstaal PJ, Breteler MM. Incidence of parkinsonism and Parkinson disease in a general population: the Rotterdam Study. Neurology. 2004;63: $1240-1244$.

3. Dorsey ER, Constantinescu R, Thompson JP, et al. Projected number of people with Parkinson disease in the most populous nations, 2005 through 2030. Neurology. 2007;68:384-386. 
4. Cotzias MH, Van Woert, Schiffer LM. Aromatic amino acids and modification of parkinsonism. N Engl J Med. 1967;276:374-379.

5. Braak H, Del Tredici K, Rüb U, de Vos RA, Jansen Steur EN, Braak E. Staging of brain pathology related to sporadic Parkinson's disease. Neurobiol Aging. 2003;24:197-211.

6. Zarow C, Lyness SA, Mortimer JA, Chui HC. Neuronal loss is greater in the locus coeruleus than nucleus basalis and substantia nigra in Alzheimer and Parkinson diseases. Arch Neurol. 2003;60:337-341.

7. Hawkes CH, Del Tredici K, Braak H. A timeline for Parkinson's disease. Parkinsonism Relat Disord. 2010;16:79-84.

8. Booth B, Zemmel R. Prospects for productivity. Nat Rev Drug Discov. 2004;3:451-456.

9. Lou K, de Rond M. The 'not invented here' myth. Nat Rev Drug Discov. 2006;5:451-452.

10. Muller T. New small molecules for the treatment of Parkinson's disease Expert Opin Investig Drugs. 2010;19:1077-1086.

11. Goetz CG, Damier P, Hicking C. Sarizotan as a treatment for dyskinesias in Parkinson's disease: a double-blind placebo-controlled trial. Mov Disord. 2007;22:179-186.

12. DiMasi JA, Hansen RW, Grabowski HG. The price of innovation: new estimates of drug development costs. J Health Econ. 2003;22:151-185.

13. de Vries HE, Witte M, Hondius D, et al. Nrf2-induced antioxidant protection: a promising target to counteract ROS-mediated damage in neurodegenerative disease? Free Radic Biol Med. 2008;45:1375-1383.

14. Nolan GP. What's wrong with drug screening today. Nat Chem Biol. 2007;3:187-191

15. Young DW, Bender A, Hoyt J, et al. Integrating high-content screening and ligand-target prediction to identify mechanism of action. Nat Chem Biol. 2008;4:59-68.

16. Ma P, Zemmel R. Value of novelty? Nat Rev Drug Discov. 2002;1 571-572.

17. Rezak M. Current pharmacotherapeutic treatment options in Parkinson's disease. Dis Mon. 2007;53:214-222.

18. Zimprich A, Biskup S, Leitner P, et al. Mutations in LRRK2 cause autosomal-dominant parkinsonism with pleomorphic pathology. Neuron. 2004;44:601-607.

19. Paisan-Ruiz C, Jain S, Evans EW, et al. Cloning of the gene containing mutations that cause PARK8-linked Parkinson's disease. Neuron. 2004;44:595-600.

20. Polymeropoulos MH, Lavedan C, Leroy E, et al. Mutation in the alphasynuclein gene identified in families with Parkinson's disease. Science. 1997;276:2045-2047.

21. Kitada T, Asakawa S, Hattori N, et al. Mutations in the parkin gene cause autosomal recessive juvenile parkinsonism. Nature. 1998;392:605-608.

22. Bonifati V, Rizzu P, van Baren MJ, et al. Mutations in the DJ-1 gene associated with autosomal recessive early-onset parkinsonism. Science. 2003;299:256-259.

23. Valente EM, Abou-Sleiman PM, Caputo V, et al. Hereditary early-onset Parkinson's disease caused by mutations in PINK1. Science. 2004;304: 1158-1160.

24. Ramirez A, Heimbach A, Gründemann J, et al. Hereditary parkinsonism with dementia is caused by mutations in ATP13A2, encoding a lysosomal type 5 P-type ATPase. Nat Genet. 2006;38:1184-1191.

25. Wood-Kaczmar A, Gandhi S, Wood NW. Understanding the molecular causes of Parkinson's disease. Trends Mol Med. 2006;12:521-528.

26. Malkus KA, Tsika E, Ischiropoulos H. Oxidative modifications, mitochondrial dysfunction, and impaired protein degradation in Parkinson's disease: how neurons are lost in the Bermuda triangle. Mol Neurodegener. 2009;4:24.

27. Lewy FH. Paralysis agitans. I. Pathologische anatomie. Handbuch der Neurologie. [Paralysis agitans. I. Pathological anatomy. Handbook of Neurology.] Berlin: Springer; 1912: 920-933.

28. Schapira AH, Cooper JM, Dexter D, Clark JB, Jenner P, Marsden CD Mitochondrial complex I deficiency in Parkinson's disease. J Neurochem. 1990;54:823-827.

29. Finkbeiner S, Cuervo AM, Morimoto RI, Muchowski PJ. Disease-modifying pathways in neurodegeneration. $J$ Neurosci. 2006;26:10349-10357.
30. Lim KL, Ng CH. Genetic models of Parkinson disease. Biochim Biophys Acta. 2009;1792:604-615.

31. Bove J, Prou D, Perier C, Przedborski S. Toxin-induced models of Parkinson's disease. Neuro Rx. 2005;2:484-494.

32. Fornai F, Schlüter OM, Lenzi P, et al. Parkinson-like syndrome induced by continuous MPTP infusion: convergent roles of the ubiquitinproteasome system and alpha-synuclein. Proc Natl Acad Sci U S A. 2005;102:3413-3418.

33. Lee BD, Shin JH, VanKampen J, et al. Inhibitors of leucine-rich repeat kinase-2 protect against models of Parkinson's disease. Nat Med. 2010;16:998-1000.

34. Lin X, Parisiadou L, Gu XL, et al. Leucine-rich repeat kinase 2 regulates the progression of neuropathology induced by Parkinson's-diseaserelated mutant alpha-synuclein. Neuron. 2009;64:807-827.

35. Yoon IS, Au Q, Barber JR, Ng SC, Zhang B. Development of a highthroughput screening assay for cytoprotective agents in rotenoneinduced cell death. Anal Biochem. 2010;407:205-210.

36. Falkenburger BH, Schulz JB. Limitations of cellular models in Parkinson's disease research. J Neural Transm Suppl. 2006;70:261-268.

37. Marx FP, Holzmann C, Strauss KM, et al. Identification and functional characterization of a novel R621C mutation in the synphilin-1 gene in Parkinson's disease. Hum Mol Genet. 2003;12:1223-1231.

38. Shendelman S, Jonason A, Martinat C, Leete T, Abeliovich A. DJ-1 is a redox-dependent molecular chaperone that inhibits alpha-synuclein aggregate formation. PLoS Biol. 2004;2:e362.

39. Zhou W, Freed CR. Tyrosine-to-cysteine modification of human alphasynuclein enhances protein aggregation and cellular toxicity. $J$ Biol Chem. 2004;279:10128-10135.

40. Zhou W, Hurlbert MS, Schaack J, Prasad KN, Freed CR. Overexpression of human alpha-synuclein causes dopamine neuron death in rat primary culture and immortalized mesencephalon-derived cells. Brain Res. 2000;866:33-43.

41. Yang F, Yang YP, Mao CJ, et al. Role of autophagy and proteasome degradation pathways in apoptosis of PC12 cells overexpressing human alpha-synuclein. Neurosci Lett. 2009;454:203-208.

42. Lotharius J, Barg S, Wiekop P, Lundberg C, Raymon HK, Brundin P. Effect of mutant alpha-synuclein on dopamine homeostasis in a new human mesencephalic cell line. J Biol Chem. 2002;277: 38884-38894.

43. Eglen RM, Gilchrist A, Reisine T. The use of immortalized cell lines in GPCR screening: the good, bad and ugly. Comb Chem High-throughput Screen. 2008;11:560-565.

44. Do JH, Kim IS, Park TK, Choi DK. Genome-wide examination of chromosomal aberrations in neuroblastoma SH-SY5Y cells by array-based comparative genomic hybridization. Mol Cells. 2007;24:105-112.

45. Kenakin TP. New eyes to see texture in ligand efficacy. Nat Methods. $2005 ; 2: 163-164$

46. Kola I, Landis H. Can the pharmaceutical industry reduce attrition rates? Nat Rev Drug Discov. 2004;3:711-715.

47. Eglen RM, Gilchrist A, Reisine T. An overview of drug screening using primary and embryonic stem cells. Comb Chem High-throughput Screen. 2008;11:566-572.

48. Mena MA, Davila V, Sulzer D. Neurotrophic effects of L-DOPA in postnatal midbrain dopamine neuron/cortical astrocyte cocultures. J Neurochem. 1997;69:1398-1408.

49. Heyer EJ. Electrophysiological study of mammalian neurons from ventral mesencephalon grown in primary dissociated cell culture. Brain Res. 1984;310:142-148.

50. Chiodo LA, Bunney BS. Population response of midbrain dopaminergic neurons to neuroleptics: further studies on time course and nondopaminergic neuronal influences. J Neurosci. 1987;7:629-633.

51. Rayport S, Sulzer D, Shi WX. Identified postnatal mesolimbic dopamine neurons in culture: morphology and electrophysiology. $J$ Neurosci. 1992;12:4264-4280.

52. McNaught KS, Shashidharan P, Perl DP, Jenner P, Olanow CW. Aggresome-related biogenesis of Lewy bodies. Eur J Neurosci. 2002;16:2136-2148. 
53. Staropoli JF, McDermott C, Martinat C, Schulman B, Demireva E, Abeliovich A. Parkin is a component of an SCF-like ubiquitin ligase complex and protects postmitotic neurons from kainate excitotoxicity. Neuron. 2003;37:735-749.

54. Freed CR, Greene PE, Breeze RE, et al. Transplantation of embryonic dopamine neurons for severe Parkinson's disease. $N$ Engl J Med. 2001;344:710-719.

55. Li JY, Englund E, Holton JL, et al. Lewy bodies in grafted neurons in subjects with Parkinson's disease suggest host-to-graft disease propagation. Nat Med. 2008;14:501-503.

56. Zhou W, Schaack J, Zawada WM, Freed CR. Overexpression of human alpha-synuclein causes dopamine neuron death in primary human mesencephalic culture. Brain Res. 2002;926:42-50.

57. McNeish JD. Stem cells as screening tools in drug discovery. Curr Opin Pharmacol. 2007;7:515-520.

58. Pouton CW, Haynes JM. Embryonic stem cells as a source of models for drug discovery. Nat Rev Drug Discov. 2007;6:605-616.

59. McNeish J. Embryonic stem cells in drug discovery. Nat Rev Drug Discov. 2004;3:70-80.

60. Lazic SE, Barker RA. The future of cell-based transplantation therapies for neurodegenerative disorders. J Hematother Stem Cell Res. 2003; 12:635-642.

61. Kawasaki H, Suemori H, Mizuseki K, et al. Generation of dopaminergic neurons and pigmented epithelia from primate ES cells by stromal cell-derived inducing activity. Proc Natl Acad Sci U S A. 2002;99: $1580-1585$

62. Kawasaki H, Mizuseki K, Nishikawa S. Induction of midbrain dopaminergic neurons from ES cells by stromal cell-derived inducing activity. Neuron. 2000;28:31-40.

63. Lee SH, Lumelsky N, Studer L, Auerbach JM, McKay RD. Efficient generation of midbrain and hindbrain neurons from mouse embryonic stem cells. Nat Biotechnol. 2000;18:675-679.

64. Raye WS, Tochon-Danguy N, Pouton CW, Haynes JM. Heterogeneous population of dopaminergic neurons derived from mouse embryonic stem cells: preliminary phenotyping based on receptor expression and function. Eur J Neurosci. 2007;25:1961-1970.

65. Kim JH, Auerbach JM, Rodríguez-Gómez JA, et al. Dopamine neurons derived from embryonic stem cells function in an animal model of Parkinson's disease. Nature. 2002;418:50-56.

66. Ben-Hur T, Idelson M, Khaner H. Transplantation of human embryonic stem cell-derived neural progenitors improves behavioral deficit in Parkinsonian rats. Stem Cells. 2004;22:1246-1255.

67. Bjorklund LM, Sánchez-Pernaute R, Chung S, et al. Embryonic stem cells develop into functional dopaminergic neurons after transplantation in a Parkinson rat model. Proc Natl Acad Sci U S A. 2002;99:2344-2349.

68. Park CH, Minn YK, Lee JY, et al. In vitro and in vivo analyses of human embryonic stem cell-derived dopamine neurons. J Neurochem. 2005; 92:1265-1276.

69. Perrier AL, Tabar V, Barberi T, et al. Derivation of midbrain dopamine neurons from human embryonic stem cells. Proc Natl Acad Sci USA. 2004;101:12543-12548.

70. Zeng X, Cai J, Chen J, et al. Dopaminergic differentiation of human embryonic stem cells. Stem Cells. 2004;22:925-940.

71. Morizane A, Darsalia V, Guloglu MO. A simple method for large-scale generation of dopamine neurons from human embryonic stem cells. J Neurosci Res. 2010;88:3467-3478.

72. Cooper O, Hargus G, Deleidi M, et al. Differentiation of human ES and Parkinson's disease induced pluripotent stem cells into ventral midbrain dopaminergic neurons requires a high activity form of SHH, FGF8a and specific regionalization by retinoic acid. Mol Cell Neurosci. 2010;45: $258-266$.

73. Nunes MC, Roy NS, Keyoung HM, et al. Identification and isolation of multipotential neural progenitor cells from the subcortical white matter of the adult human brain. Nat Med. 2003;9:439-447.

74. Reynolds BA, Weiss S. Generation of neurons and astrocytes from isolated cells of the adult mammalian central nervous system. Science. 1992;255:1707-1710.
75. Wright LS, Prowse KR, Wallace K, Linskens MH, Svendsen CN. Human progenitor cells isolated from the developing cortex undergo decreased neurogenesis and eventual senescence following expansion in vitro. Exp Cell Res. 2006;312:2107-2120.

76. Kim SU. Human neural stem cells genetically modified for brain repair in neurological disorders. Neuropathology. 2004;24: 159-171.

77. Donato R, Miljan EA, Hines SJ, et al. Differential development of neuronal physiological responsiveness in two human neural stem cell lines. BMC Neurosci. 2007;8:36.

78. Wood-Kaczmar A, Gandhi S, Yao Z, et al. PINK1 is necessary for long term survival and mitochondrial function in human dopaminergic neurons. PLoS One. 2008; 3:e2455.

79. Pruszak J, Sonntag KC, Aung MH, Sanchez-Pernaute R, Isacson O. Markers and methods for cell sorting of human embryonic stem cellderived neural cell populations. Stem Cells. 2007;25:2257-2268.

80. Li M, Pevny L, Lovell-Badge R, Smith A. Generation of purified neural precursors from embryonic stem cells by lineage selection. Curr Biol. 1998;8:971-974.

81. Zhou W, Lee YM, Guy VC, Freed CR. Embryonic stem cells with GFP knocked into the dopamine transporter yield purified dopamine neurons in vitro and from knock-in mice. Stem Cells. 2009;27:2952-2961.

82. Schneider BL, Seehus CR, Capowski EE, Aebischer P, Zhang SC, Svendsen CN. Over-expression of alpha-synuclein in human neural progenitors leads to specific changes in fate and differentiation. Hum Mol Genet. 2007;16:651-666.

83. Martinat C, Shendelman S, Jonason A, et al. Sensitivity to oxidative stress in DJ-1-deficient dopamine neurons: an ES-derived cell model of primary Parkinsonism. PLoS Biol. 2004;2:e327.

84. McNeish J, Roach M, Hambor J, et al. High-throughput screening in embryonic stem cell-derived neurons identifies potentiators of alphaamino-3-hydroxyl-5-methyl-4-isoxazolepropionate-type glutamate receptors. J Biol Chem. 2010;285:17209-17217.

85. Paquette JA, Kumpf SW, Streck RD, Thomson JJ, Chapin RE, Stedman DB. Assessment of the embryonic stem cell test and application and use in the pharmaceutical industry. Birth Defects Res B Dev Reprod Toxicol. 2008;83:104-111.

86. Seiler A, Visan A, Buesen R, Genschow E, Spielmann H. Improvement of an in vitro stem cell assay for developmental toxicity: the use of molecular endpoints in the embryonic stem cell test. Reprod Toxicol. 2004;18:231-240.

87. Takahashi K, Yamanaka S. Induction of pluripotent stem cells from mouse embryonic and adult fibroblast cultures by defined factors. Cell. 2006;126:663-676.

88. Okita K, Ichisaka T, Yamanaka S. Generation of germline-competent induced pluripotent stem cells. Nature. 2007;448:313-317.

89. Swistowski A, Peng J, Liu Q, et al. Efficient generation of functional dopaminergic neurons from human induced pluripotent stem cells under defined conditions. Stem Cells. 2010;28:1893-1904.

90. Soldner F, Hockemeyer D, Beard C, et al. Parkinson's disease patientderived induced pluripotent stem cells free of viral reprogramming factors. Cell. 2009;136:964-977.

91. Wernig M, Zhao JP, Pruszak J, et al. Neurons derived from reprogrammed fibroblasts functionally integrate into the fetal brain and improve symptoms of rats with Parkinson's disease. Proc Natl Acad Sci U S A. 2008;105:5856-5861.

92. Niclis JC, Trounson AO, Dottori M, et al. Human embryonic stem cell models of Huntington disease. Reprod Biomed Online. 2009;19: 106-113.

93. Maj MC, Tkachyova I, Patel P, et al. Oxidative stress alters the regulatory control of p66Shc and Akt in PINK1 deficient cells. Biochem Biophys Res Commun. 2010;399:331-335.

94. Rakovic A, Grünewald A, Seibler P, et al. Effect of endogenous mutant and wild-type PINK1 on Parkin in fibroblasts from Parkinson disease patients. Hum Mol Genet. 2010;19:3124-3137.

95. Park IH, Arora N, Huo H, et al. Disease-specific induced pluripotent stem cells. Cell. 2008;134:877-886. 
96. Hargus G, Cooper O, Deleidi M, et al. Differentiated Parkinson patientderived induced pluripotent stem cells grow in the adult rodent brain and reduce motor asymmetry in Parkinsonian rats. Proc Natl Acad Sci U S A. 2010;107:15921-15926.

97. Grealish S, Jönsson ME, Li M, Kirik D, Björklund A, Thompson LH. The A9 dopamine neuron component in grafts of ventral mesencephalon is an important determinant for recovery of motor function in a rat model of Parkinson's disease. Brain. 2010;133(Pt 2):482-495.

98. Elsworth JD, Deutch AY, Redmond DE Jr, Sladek JR Jr, Roth RH. MPTP-induced parkinsonism: relative changes in dopamine concentration in subregions of substantia nigra, ventral tegmental area and retrorubral field of symptomatic and asymptomatic vervet monkeys. Brain Res. 1990;513:320-324.

99. Zigmond MJ, Abercrombie ED, Berger TW, Grace AA, Stricker EM. Compensations after lesions of central dopaminergic neurons: some clinical and basic implications. Trends Neurosci. 1990;13:290-296.

100. Zigmond MJ,Acheson AL, Stachowiak MK, Stricker EM. Neurochemical compensation after nigrostriatal bundle injury in an animal model of preclinical parkinsonism. Arch Neurol. 1984;41:856-861.

101. Nguyen HN, Byers B, Cord B, et al. LRRK2 mutant iPSC-derived DA neurons demonstrate increased susceptibility to oxidative stress. Cell Stem Cell. 2011;8:267-280.

102. Hockemeyer D, Soldner F, Beard C, et al. Efficient targeting of expressed and silent genes in human embryonic stem cells and iPSCs using zinc-finger nucleases. Nat Biotechnol. 2009;27:851-857.

103. Zou J, Maeder ML, Mali P, et al. Gene targeting of a disease-related gene in human induced pluripotent stem and embryonic stem cells. Cell Stem Cell. 2009;5:97-110.

104. Change N, Mercier G, Lucotte G. Genetic screening of the G2019S mutation of the LRRK2 gene in Southwest European, North African, and Sephardic Jewish subjects. Genet Test. 2008;12:333-339.

105. Laurent LC, Nievergelt CM, Lynch C, et al. Restricted ethnic diversity in human embryonic stem cell lines. Nat Methods. 2010;7:6-7.

106. Carr J, de la Fuente-Fernández R, Schulzer M, et al. Familial and sporadic Parkinson's disease usually display the same clinical features. Parkinsonism Relat Disord. 2003;9:201-204.

107. Langston JW. The Parkinson's complex: parkinsonism is just the tip of the iceberg. Ann Neurol. 2006;59:591-596.

108. Selikhova M, Williams DR, Kempster PA, Holton JL, Revesz T, Lees AJ. A clinico-pathological study of subtypes in Parkinson's disease. Brain. 2009;132(Pt 11):2947-2957.

109. Lesage S, Brice A. Parkinson's disease: from monogenic forms to genetic susceptibility factors. Hum Mol Genet. 2009;18:R48-R59.

110. Osafune K, Caron L, Borowiak M, et al. Marked differences in differentiation propensity among human embryonic stem cell lines. Nat Biotechnol. 2008;26:313-315.

111. Choi KD, Yu J, Smuga-Otto K, et al. Hematopoietic and endothelial differentiation of human induced pluripotent stem cells. Stem Cells. 2009;27:559-567.

112. Bordet T, Buisson B, Michaud M, et al. Identification and characterization of cholest-4-en-3-one, oxime (TRO19622), a novel drug candidate for amyotrophic lateral sclerosis. J Pharmacol Exp Ther. 2007;322: 709-720.

113. Barbaric I, Gokhale PJ, Andrews PW. High-content screening of small compounds on human embryonic stem cells. Biochem Soc Trans. 2010;38:1046-1050.
114. Jain S, Heutink P. From single genes to gene networks: highthroughput-high-content screening for neurological disease. Neuron. 2010;68:207-217.

115. Daub A, Sharma P, Finkbeiner S. High-content screening of primary neurons: ready for prime time. Curr Opin Neurobiol. 2009; 19:537-543.

116. Jones TR, Carpenter AE, Lamprecht MR, et al. Scoring diverse cellular morphologies in image-based screens with iterative feedback and machine learning. Proc Natl Acad Sci U S A. 2009;106:1826-1831.

117. Arrasate M, Finkbeiner S. Automated microscope system for determining factors that predict neuronal fate. Proc Natl Acad Sci U S A. 2005;102:3840-3845.

118. Arrasate M, Mitra S, Schweitzer ES, Segal MR, Finkbeiner S. Inclusion body formation reduces levels of mutant huntingtin and the risk of neuronal death. Nature. 2004;431:805-810.

119. Miller J, Arrasate M, Shaby BA, Mitra S, Masliah E, Finkbeiner S. Quantitative relationships cbetween huntingtin levels, polyglutamine length, inclusion body formation, and neuronal death provide novel insight into Huntington's disease molecular pathogenesis. J Neurosci. 2010;30:10541-10550.

120. Mitra S, Tsvetkov AS, Finkbeiner S. Single neuron ubiquitinproteasome dynamics accompanying inclusion body formation in Huntington disease. $J$ Biol Chem. 2009;284:4398-4403.

121. Barmada SJ, Skibinski G, Korb E, Rao EJ, Wu JY, Finkbeiner S. Cytoplasmic mislocalization of TDP-43 is toxic to neurons and enhanced by a mutation associated with familial amyotrophic lateral sclerosis. J Neurosci. 2010;30:639-649.

122. Cookson MR. Alpha-synuclein and neuronal cell death. Mol Neurodegener. 2009;4:9.

123. Lucking CB, Dürr A, Bonifati V, et al. Association between early-onset Parkinson's disease and mutations in the parkin gene. $N$ Engl $J$ Med. 2000;342:1560-1567.

124. Shimura H, Hattori N, Kubo S, et al. Familial Parkinson disease gene product, parkin, is a ubiquitin-protein ligase. Nat Genet 2000;25:302-305.

125. Narendra D, Tanaka A, Suen DF, Youle RJ. Parkin is recruited selectively to impaired mitochondria and promotes their autophagy. $J$ Cell Biol. 2008;183:795-803.

126. Klein C, Grunewald A, Hedrich K. Early-onset parkinsonism associated with PINK1 mutations: frequency, genotypes, and phenotypes. Neurology. 2006;66:1129-1130.

127. Yao Z, Wood NW. Cell death pathways in Parkinson's disease: role of mitochondria. Antioxid Redox Signal. 2009;11:2135-2149.

128. Narendra DP, Jin SM, Tanaka A, et al. PINK1 is selectively stabilized on impaired mitochondria to activate Parkin. PLoS Biol. 2010;8:e1000298.

129. Paisan-Ruiz C, Nath P, Washecka N, Gibbs JR, Singleton AB Comprehensive analysis of LRRK2 in publicly available Parkinson's disease cases and neurologically normal controls. Hum Mutat. 2008;29:485-490.

130. Daniels V, Baekelandt V, Taymans JM. On the road to leucine-rich repeat kinase 2 signalling: evidence from cellular and in vivo studies Neurosignals. 2011;19:1-15.
International Journal of High Throughput Screening

\section{Publish your work in this journal}

International Journal of High Throughput Screening is an international, peer-reviewed, open access journal publishing original research, reports, editorials, reviews and commentaries dedicated to all aspects of high throughput screening, especially related to drug discovery and associated areas of biology and chemistry. The manuscript management sys-

\section{Dovepress}

tem is completely online and includes a very quick and fair peer-review system. Visit http://www.dovepress.com/testimonials.php to read real quotes from published authors. 